\title{
A big challenge to patients with Inflammatory bowel disease: COVID-19
}

\author{
Rui Song ${ }^{1}$, Jiahe Tan ${ }^{1}$, Shengtao Liao ${ }^{1}$, Zhechuan Mei ${ }^{1}$, Hanqing Zeng ${ }^{1}$, and Lin $\mathrm{Lv}^{1}$ \\ ${ }^{1}$ Chongqing Medical University Affiliated Second Hospital
}

May 5, 2020

\begin{abstract}
In December 2019, many people in Wuhan, the capital city of Hubei, China developed an infection and respiratory symptoms from an unknown virus. Within a month, scientists named the novel corona-virus as 2019-nCoV, and the WHO subsequently named the disease produced by SARS-CoV-2 as COVID-19. Shortly, the COVID-19 rapidly spread through almost worldwide. The WHO declared a global health emergency on January 30, 2020 and pandemic status on March 11, 2020, respectively. Since SARS-CoV-2 RNA was first detected in a stool specimen and the autopsy report for a man with COVID-19 which showed segmental dilatation and stenosis in the small intestine, much attention has been paid to the gastrointestinal tract infection of SARS-CoV-2. Especially in the context of inflammatory bowel disease( IBD), several questions arise. The biggest concern is if patients with IBD have an increased or a decreased risk to suffer from COVID-19? Although research has not figured out the susceptibility of IBD patients to virus infection, immunosuppressive drugs were considered potential risk factors. Besides the recommendations provided to the general population, patients with IBD need more professional advice.
\end{abstract}

\section{Hosted file}

COVID-19 and IBD.doc available at https://authorea.com/users/316943/articles/447051-a-bigchallenge-to-patients-with-inflammatory-bowel-disease-covid-19

\section{Hosted file}

Tables.docx available at https://authorea.com/users/316943/articles/447051-a-big-challengeto-patients-with-inflammatory-bowel-disease-covid-19 


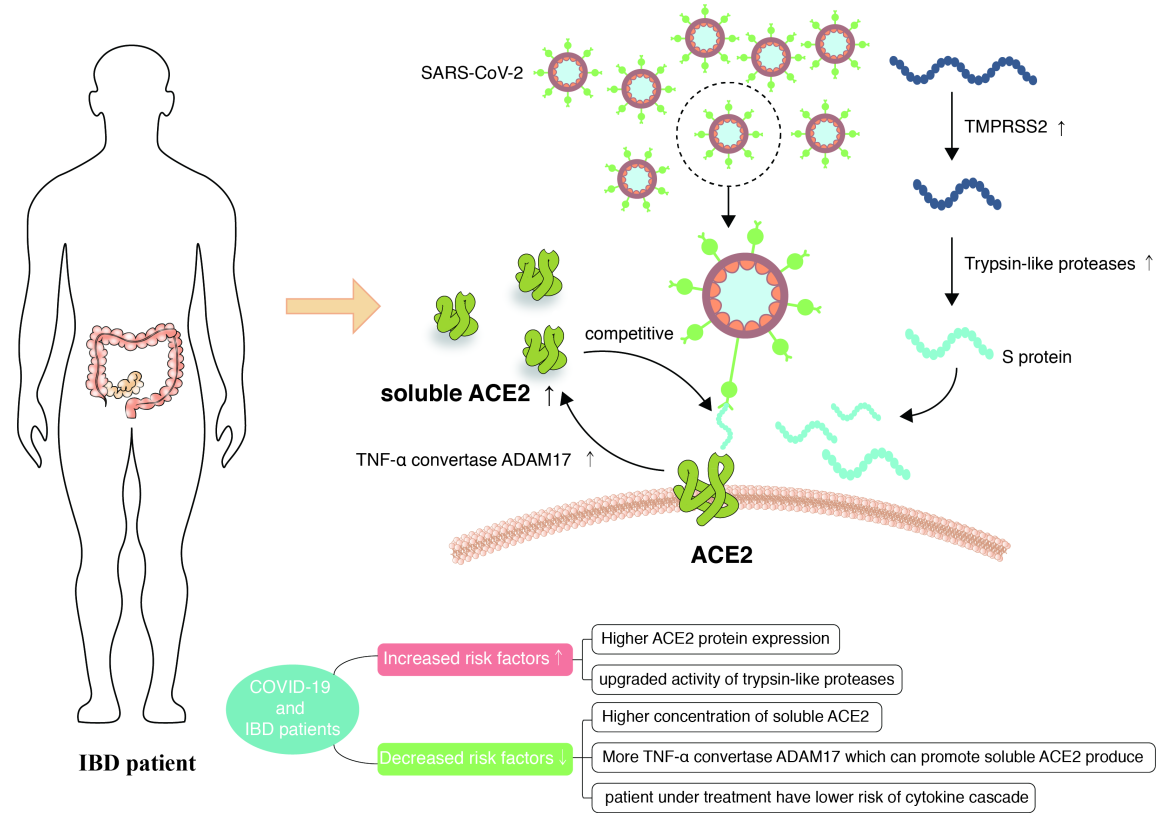

